\title{
Depression as a risk factor for adverse outcomes in coronary heart disease
}

\author{
Kenneth E Freedland ${ }^{*}$ and Robert M Carney
}

\begin{abstract}
Background: Depression is firmly established as an independent predictor of mortality and cardiac morbidity in patients with coronary heart disease (CHD). However, it has been difficult to determine whether it is a causal risk factor, and whether treatment of depression can improve cardiac outcomes. In addition, research on biobehavioral mechanisms has not yet produced a definitive causal model of the relationship between depression and cardiac outcomes.

Discussion: Key challenges in this line of research concern the measurement of depression, the definition and relevance of certain subtypes of depression, the temporal relationship between depression and CHD, underlying biobehavioral mechanisms, and depression treatment efficacy.
\end{abstract}

Summary: This article examines some of the methodological challenges that will have to be overcome in order to determine whether depression should be regarded as a key target of secondary prevention in CHD.

Keywords: Acute coronary syndrome, Antidepressive agents, Coronary disease, Depression, Depressive disorder, Mortality, Myocardial infarction, Psychotherapy

\section{Background}

The past three decades of research have produced compelling evidence that depression is a risk factor for mortality and cardiac morbidity in patients with coronary heart disease (CHD) [1-5]. Nevertheless, many questions about this phenomenon have not yet been answered unequivocally, and skeptics still have some legitimate grounds for their skepticism.

The most important scientific questions about depression in patients with CHD are whether it is not just a risk marker but a causal risk factor for adverse CHD outcomes [6], and which biobehavioral mechanisms, among the many that have been proposed, link depression to these outcomes $[7,8]$. The most important clinical questions are whether depression is modifiable (that is, treatable) in patients with CHD, and whether its treatment improves cardiac event-free survival [9].

This article explains some of the principal reasons why it has been difficult to answer these questions to a high degree of certainty. It discusses methodological challenges, observational research, randomized controlled trials

\footnotetext{
* Correspondence: freedlak@bmc.wustl.edu

Department of Psychiatry, Washington University School of Medicine, 4320 Forest Park Avenue, Suite 301, St Louis, Missouri 63108, USA
}

(RCTs), and other treatment-related research. It also highlights an interesting paradox that has recently emerged in the treatment literature, and discusses its implication for future research.

\section{Discussion}

\section{Defining and measuring depression}

Several long-standing controversies have surrounded the definition and measurement of depression in patients with CHD. The central question that drives these controversies is whether features that resemble depression represent 'real' depression in these patients. This question is not exclusive to CHD; it also casts doubt on the diagnostic validity of depression in the presence of other chronic medical illnesses [10]. One of the reasons is that some of the symptoms of depression are non-specific; that is, they can also be symptoms of other disorders [11]. Fatigue is a good example. In a patient with CHD, it might be due to depression, but it could also be due to CHD, medical comorbidities, side effects of medications, or deconditioning. One way to handle non-specific symptoms is to assume that they are not due to depression and to omit them from screening instruments and

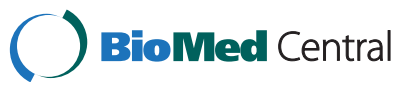


diagnostic interviews [12]. This approach is problematic, for several reasons. First, in many cases, these symptoms may be due partially or entirely to depression, and it is rarely possible to pinpoint their etiology. Second, there are fairly strong correlations, even in medically ill patient populations, between non-specific symptoms such as fatigue and less ambiguous cognitive and emotional symptoms of depression such as dysphoric mood, feelings of worthlessness, and excessive or inappropriate guilt $[13,14]$. Finally, the American Psychiatric Association's Diagnostic and Statistical Manual of Mental Disorders, fourth edition (DSM-IV) criteria for depressive disorders [15] indicate that features such as fatigue should be counted as symptoms of depression unless they are '...due to the direct physiological effects of a substance (for example, a drug of abuse, a medication) or a general medical condition (for example, hypothyroidism)'. In other words, unless there is clear evidence that a symptom is entirely due to the direct, physiological effects of a medical condition or medication, it should be counted towards the diagnosis of depression.

Giving the benefit of the doubt to non-specific symptoms may increase the risk of false positive diagnoses of depression. However, the DSM-IV criteria for major depression reduce this risk by requiring (1) the presence of at least one cardinal symptom (dysphoric mood and/or pervasive loss of interest or pleasure in usual activities) plus four or five additional symptoms from a list of nine distinguishing features of depression, (2) the symptoms must be present most of the day nearly every day, (3) the symptoms must have been present for at least 2 weeks, and (4) there should be evidence that the symptoms are causing distress and/or impairment in one or more domains of daily functioning.

The cognitive and emotional symptoms of depression in cardiac patients are sometimes disregarded as well, but for a very different reason: The importance of these symptoms is minimized because they are 'understandable', as in, 'Of course he's feeling down, he just had a heart attack' [16]. This view is unjustified. If a depressive episode is precipitated by a stressful event, regardless of whether it is a myocardial infarction (MI) or any other kind of adversity, it is still a depressive episode. Relatively severe and/or persistent cases of depression are clinically significant regardless of whether their etiology is 'understandable' or obscure. In addition, it is a mistake to assume that if a patient is found to be depressed after an adverse event such as an MI, the depression is necessarily due to that event. Many patients have a myocardial infarction during a depressive episode that may have started weeks or months before the cardiac event [17]. Furthermore, many patients start having depressive episodes years or even decades before there are any clinical manifestations of CHD [18].
These controversies would have succumbed long ago if there were a definitive diagnostic test for depression or if it were a monogenic disorder, but depression is a complex, multifactorial condition, and there is no definitive laboratory test for it. The research in this area is further complicated by a multiplicity of measures of depression. Some of the most frequently used instruments are listed in Table 1. The list is limited to measures that were recommended for use in research on depression and CHD in a National Heart, Lung, and Blood working group report, and that have been used in multiple studies of cardiac patients [19].

In retrospective studies of large healthcare databases, depression is typically defined by clinical diagnosis and/ or antidepressant prescriptions. Despite the fact that these sorts of studies are plagued by classification errors, some of them have found significant associations between depression and adverse outcomes in cardiac patients, for example $[27,28]$.

In many prospective studies, depression has been measured by self-report questionnaires $[17,29,30]$. The total score can be used to characterize the overall severity of depressive symptoms. Cutoff scores can be used to differentiate between non-depressed and depressed patients, and scores in the depressed range may be subdivided into mild, moderate, and severe levels of depression. Several different questionnaires have been used to study depression in cardiac patients, despite the fact that there are differences in their predictive values [31-34]. In other prospective studies, depression is defined according to the DSM-IV or International Classification of Diseases, ninth revision (ICD-9) criteria for depressive disorders [35-37]. The symptoms of depressive disorders are usually evaluated in these studies by a structured interview rather than by a self-report questionnaire [35,36,38]. Some studies suggest that interview-based depression diagnoses have greater predictive value than questionnaires vis-à-vis cardiac outcomes; other studies suggest the opposite. The jury is still out on this question, but it is clear that differences among measurement methods help to explain differences among studies as to whether and how strongly depression predicts cardiac outcomes [39,40].

Table 1 Some widely used measures of depression in research on coronary heart disease (CHD)

\begin{tabular}{ll}
\hline Format & Instruments and reference \\
\hline Self-report & Patient Health Questionnaire (PHQ) [20-22] \\
& Beck Depression Inventory, first edition (BDI) [23] \\
& Beck Depression Inventory, second edition (BDI-II) [24] \\
Structured interview & Composite International Diagnostic Interview \\
& (CIDI) [25] \\
& Depression Interview and Structured Hamilton \\
& (DISH) [26] \\
\hline
\end{tabular}




\section{Subtypes of depression}

Depression is a polythetic syndrome in which different patients present with different combinations of symptoms [41]. For example, sleep disturbance is a prominent feature of depression in some cases but not in others [42]. The phenotypic complexity of depression has created interest in the question of whether particular symptoms of depression, or clusters of symptoms, are associated with a higher risk of adverse cardiac outcomes than are other symptoms or symptom clusters. Although there are a number of different lines along which the syndrome of depression has been carved, the cognitive/somatic distinction is the one that has gained the most attention in the behavioral cardiology literature [43-48].

Research on the cognitive and somatic features of depression in cardiac patients can be difficult to interpret, for several reasons. First, there several different ways to group or cluster these symptoms, including various forms of statistical factor analysis and 'face validity' approaches. Different methods can and do result in different groupings [43-47,49-53]. Second, many studies have shown that there is a moderately strong correlation between the cognitive and the somatic symptoms of depression, and that both sets of symptoms tend to rise and fall along with the overall severity of depression. The cognitive and somatic symptoms of depression are probably manifestations of a single polythetic disorder, not indicators of two distinctly different disorders $[13,14]$. Finally, studies that have compared the predictive values of cognitive and somatic symptoms have produced conflicting results. Some studies of patients with coronary disease have shown that somatic symptoms are better predictors of cardiac outcomes than are cognitive symptoms, but other studies have not found this difference $[44,49,54]$. Studies of other cardiac patient populations have increased the heterogeneity of the findings in this area. For example, studies of depression after coronary artery bypass graft (CABG) surgery shown that cognitive symptoms are better predictors than are somatic symptoms, the very opposite of the pattern found in some studies of post-acute coronary syndrome (ACS) patients $[55,56]$.

\section{Time factors}

Coronary atherosclerosis usually starts to develop long before it produces any clinical manifestations or requires intervention. Its initial clinical presentation is often lethal, and relatively little is known about the role of depression in these cases. Thus, most of what we know about the effect of depression on cardiac outcomes is based on studies of patients who have survived the clinical onset of CHD. Whether the strength of the effect of depression differs between patients who survive the onset of CHD and those who do not is very difficult to study.
Initial, non-lethal presentations of coronary disease come in a variety of forms, including discovery via routine testing, exertional angina, unstable angina, acute $\mathrm{MI}$, and others, and they may or may not require coronary revascularization via percutaneous intervention $(\mathrm{PCI})$ or CABG surgery. Some depression studies enroll patients after a particular kind of initial presentation, such as after an acute MI. Other studies are more inclusive and enroll patients who began their cardiac careers in a variety of different ways. In some studies, depression is assessed shortly (for example, within 1 month) after one of these initial cardiac events. In other studies, the first assessment of depression occurs long after (for example, 3 to 6 months) the initial cardiac event. In still other studies, the first assessment of depression may not follow the initial cardiac event, at least not in every case. For example, in a study of depression in patients with 'stable CHD', some of the patients may have no history of acute MI, others may have had only one MI, and still others may have had multiple MIs.

Depression is a complex condition in terms of its timing. General population studies (for example, [50]) have found that typically, the first episode of major depression occurs in childhood, adolescence, or young adulthood, but that in some cases, it occurs in middle or old age. The chronicity of major depressive episodes is also highly variable; they typically last a few weeks or months, but some last for years. In addition, there are substantial differences in the number of depressive episodes that individuals experience over their lifetime. Whereas some people have an initial episode and never have another, others go on to have multiple episodes $[57,58]$. The number of episodes an individual has had depends, in part, on the age at which he or she is assessed. Since the initial clinical presentation of CHD usually occurs after age 50, many patients have had one or more prior episodes of depression by the time they are enrolled in a study, whether or not they happen to be depressed at the time of enrollment.

It is often difficult for patients to give a reliable, accurate description of their current or recent depression symptoms. A patient might remember having felt fatigued recently, but be unable to accurately recall when it started or how frequently it has been present over the past 2 weeks. It can be even more difficult to remember depressive episodes that occurred years or even decades ago, and patient's recall of such remote events can be biased by many different factors, including their current mood state and medical condition. This can be especially problematic when patients are assessed shortly after a stressful cardiac event, for example, while hospitalized for an acute MI $[59,60]$. Inaccurate recall and reporting biases may contribute to the broader problem of underdiagnosis of depression in patients with heart disease $[11,61,62]$. 
All of these factors make it difficult to pinpoint the temporal relationship between depression and CHD. Both conditions are 'moving targets', and it can be difficult for patients to remember and report relevant details. This is unfortunate because the temporal relationship between these two conditions is important, for a variety of reasons. One is that in some prospective studies, depression is assessed only once (for example, after an acute MI), but recurrent cardiac events and deaths are ascertained over a follow-up period of up to several years. If depression predicts cardiac outcomes in such a study, it is not clear whether lasting harm was caused by the depressive episode that occurred around the index event. An alternative possibility is that the patients who were depressed at that time also tend to be depressed at other times during the follow-up. It may be that depression only poses a risk if it is present around the time of a recurrent cardiac event, and not only around the time of the index event. There is no way to differentiate between these possibilities in studies that only assess depressed after the index event.

In other prospective studies, depression is assessed periodically during the follow-up period. This is an improvement over single assessments. However, if depression is measured at very wide intervals (for example, once a year), most of the cardiac events will occur between measurements. Consequently, there will still be uncertainty as to whether patients are at risk for recurrent cardiac events only during depressive episodes, or if they remain at increased risk after or between depressive episodes.

The temporal relationship between depression and CHD may be important for other reasons as well. For example, some studies suggest that patients who have their first ever depressive episode around the time of an acute MI are at higher risk for adverse outcomes than are patients who are equally depressed but who have also had prior episodes of depression [18,63]. It could be, however, that among currently depressed MI patients, the ones who are at the highest risk are also happen to be the most likely to forget that they have had previous episodes of depression. Another possibility is that vascular disease may contribute both to cardiovascular events and to late-life depression $[64,65]$. As another example, some studies suggest that the prognostic importance of a depressive episode depends on whether its onset precedes or follows an acute coronary event [66]. Biased recall is a significant challenge in these studies, since the assessment of depression invariably occurs only after the index cardiac event.

\section{Causal models and mechanisms}

If depression predicts worse outcomes in patients with CHD (and the evidence strongly suggests that it does), then it is important to find out why. What connects these two very different conditions with one another?

Different causal models of the relationship between depression and CHD give rise to interest in different mechanisms. The model that has captivated most of the researchers in this field posits that depression plays a causal role in adverse cardiac outcomes. In this model, the adverse effects of depression on cardiac outcomes may be mediated by behavioral factors, biological factors, or both. The leading candidates on the behavioral side are factors such as physical inactivity [67], smoking [68], and non-compliance with cardiac medications [69-72]. On the biological side, the candidates that have received the most attention are cardiovascular autonomic dysregulation [73-75] and inflammation [76-83]. Depression is associated with all of these phenomena. On average, for example, depressed patients tend to have higher resting heart rates and lower heart rate variability than otherwise similar non-depressed patients. They are also more likely to smoke and less likely to engage in regular exercise and take their cardiac medications as prescribed. The addition of these factors to survival analysis models often attenuates the effect of depression on cardiac event-free survival. Thus, they might turn out to be the mechanistic linkages that explain why depressed cardiac patients are at higher risk of adverse outcomes. The expense and practical difficulty of measuring some of these biobehavioral factors, especially in large studies with lengthy follow-up periods, has impeded progress toward a definitive mechanistic model [8].

An alternative causal model posits that comorbid depression in CHD is caused by the heart disease [84]. This model assumes that the apparent effect of depression on cardiac outcomes is an epiphenomenon, that is, the patients with the most severe cases of CHD tend to have the worst outcomes and tend to be the ones who get depressed. The discussion of time factors (above) provides some reasons to question the premise that depression in patients with CHD is necessarily due to their CHD. Nevertheless, it remains possible that the patients who are the most severely depressed also tend to be the ones with the most severe CHD [4].

There are a number of ways to characterize the anatomical or pathophysiological severity of various aspects of CHD. For example, some studies have used Gensini scores to characterize the number of stenotic coronary artery segments, or cardiac enzyme levels to measure the severity of acute MI. Few studies have found that these sorts of measures correlate very strongly (if at all) with the presence or severity of depression in patients with CHD. In addition, quite a few prognostic studies have controlled for these indicators and have nevertheless found significant associations between depression and cardiac outcomes $[2,39,85]$. 
However, measures of the symptomatic or functional severity of heart disease do correlate with depression [86-89], and there is substantial evidence that depression contributes to functional impairment and lowers symptom-reporting thresholds, both in CHD and in other patient populations as well $[90,91]$. Thus, controlling for indicators of the symptomatic or functional severity of heart disease creates a 'chicken and egg' problem, and thereby contributes little to our understanding of the causal relationship between depression and adverse cardiac outcomes.

A third causal model posits that the association between depression and CHD is due to shared heritability. Studies that have tested this model have found evidence of shared heritability $[84,92,93]$. However, there is also evidence that among twins at high genetic risk for both disorders, the risk of developing ischemic heart disease is significantly higher in those with than without phenotypic expression of depression [94]. This suggests that both shared genetic liability and exposure to depression play a role, and that the relationship between depression and CHD is not an epiphenomenon.

These models are not mutually exclusive. The burden of CHD (along with other chronic illnesses that are common in patients with CHD) may promote depression, exposure to depression may promote adverse cardiac outcomes, and shared genetic factors may predispose some individuals to both conditions.

\section{Treatment research}

Two complementary goals have motivated research on the treatment of depression in patients with CHD. One is to identify treatments that are both safe and effective for depression in this patient population, and the other is to determine whether effective treatment of depression improves cardiac outcomes. The latter goal has pragmatic implications for clinical care, but it also important with respect to the question of whether depression plays a causal role in adverse cardiac outcomes.

Cardiac patients were seldom treated for depression prior to the development of selective serotonin reuptake inhibitors (SSRIs), because (among other reasons) the only antidepressants that were available at the time were cardiotoxic. Most of the recent studies of antidepressant medications for depression in cardiac patients have evaluated SSRIs such as sertraline or citalopram. The weight of the available evidence indicates that these agents are relatively safe for patients with CHD but that their efficacy is less than impressive [95-99].

The Sertraline Antidepressant Heart Attack Randomized Trial (SADHART) was one of the largest and most rigorous studies in this area. A total of 369 patients with major depression were enrolled within 1 month of an acute coronary event and randomly assigned to receive sertraline or placebo for 24 weeks. The safety results were favorable, but post-treatment scores on the Hamilton Rating Scale for Depression (HRSD) did not differ between the groups. There were significant differences on the HRSD within the subgroup of patients with severe depression, as defined by a HRSD score of 18 or higher at baseline, but not in the patients with less severe major depression. Even in the severe subgroup, the post-treatment HRSD scores of the sertraline and placebo groups differed by less than 3 points [95].

Trials that have tested psychotherapeutic interventions, or combinations of psychotherapy and medication, have also produced mixed results. The Enhancing Recovery in Coronary Heart Disease (ENRICHD) study is the largest trial to date in this area. A total of 2,481 patients were recruited within 1 month of an acute MI and met the study's criteria for depression $(\mathrm{n}=978)$, low perceived social support $(\mathrm{n}=647)$, or both $(\mathrm{n}=856)$. (Low perceived social support was an eligibility criterion for ENRICHD because, like depression, it increases the risk of adverse cardiac outcomes). The participants were randomly assigned to cognitive behavior therapy (CBT) or to usual care (UC). Some patients in the intervention arm received sertraline in addition to CBT. The intervention was superior to usual care for depression among the depressed participants, but the effect was modest; on average, the groups differed by less than 2 points on the HRSD and less than 3 points on the Beck Depression Inventory (BDI). The intervention also had statistically significant but small effects on social support among the participants who had low perceived social support at enrollment [100].

There was no difference between the treatment and control groups in cardiac event-free survival. However, ENRICHD provided a weak test of the causal risk factor hypothesis because the ENRICHD intervention had weak effects on depression and social support. It will not be possible to conduct a much stronger test of this hypothesis until more effective interventions for depression are developed. There has been some progress toward this objective [101], but we may have to wait a few more years for a rigorous, randomized, controlled test of the hypothesis that depression is a modifiable, causal risk factor for adverse cardiac outcomes in patients with CHD.

Several trials that have produced disappointing primary results have turned out to be very informative in an unexpected way. Secondary analyses of these trials have revealed that patients who remain depressed despite aggressive treatment are at significantly higher risk for adverse cardiac outcomes than are patients who do respond to treatment. Treatment-resistant depression appears to be a particularly high-risk form of depression in patients with $\mathrm{CHD}$, and a more robust predictor of 
adverse cardiac outcomes than other subtypes, such as depression with salient somatic symptoms [9].

This line of research has been productive, but its implications are disconcerting. As discussed above, the overarching goal of this entire area of research has been to determine whether depression is both modifiable and causally related to adverse cardiac outcomes. Treatmentresistant depression may be a causal risk factor for cardiac morbidity and mortality, but until we find more treatments that are efficacious this form of depression is clearly not modifiable. Treatment-resistant depression is a common problem both in otherwise medically well psychiatric patients and in patients with chronic medical comorbidities. However, coronary disease and other medical comorbidities may contribute to depression treatment resistance [102,103]. The Sequenced Treatment Alternatives to Relieve Depression (STAR*D) trial and other recent studies have shown that stepped care algorithms and non-pharmacological interventions can improve depression in many cases that do not respond to first-line treatments, but that complete remission of depression is an elusive goal in many of these cases [104-107]. Identification of more efficacious interventions for treatmentresistant depression is a high priority for research on depression in general, and in patients with coronary disease in particular.

\section{Summary}

Numerous studies and meta-analyses have shown that depression is a robust predictor of adverse outcomes in CHD. However, it has been difficult to determine whether depression plays a causal role in these outcomes, as well as the biobehavioral pathways that link depression to cardiac morbidity and mortality. It has also been difficult to determine whether effective treatment of depression can improve cardiac outcomes, primarily because highly effective treatments are not yet available. Depression is a common comorbid condition in CHD, and there is growing recognition of the harm it can cause. It is difficult to answer some of the key questions about depression in patients with CHD, but it is worth the effort to try. Further research is needed to identify significant moderators of depression treatment outcomes, and to develop efficacious interventions for treatment-resistant depression. Such studies could improve the clinical care of patients with $\mathrm{CHD}$, while helping to resolve the question of whether depression is a causal risk factor for cardiovascular morbidity and mortality in these patients.

\section{Abbreviations}

ACS: Acute coronary syndrome; BDI: Beck Depression Inventory;

CABG: Coronary artery bypass graft; CHD: Coronary heart disease;

CIDI: Composite International Diagnostic Interview; DISH: Depression Interview and Structured Hamilton; DSM-IV: Diagnostic and Statistical Manual, $4^{\text {th }}$ edition; ENRICHD: Enhancing Recovery in Coronary Heart Disease; HRSD: Hamilton Rating Scale for Depression; ICD-9: International
Classification of Diseases, $9^{\text {th }}$ edition; MI: Myocardial infarction; PCI: Percutaneous coronary intervention; PHQ: Patient Health Questionnaire; RCT: Randomized controlled trial; SADHART: Sertraline Antidepressant Heart Attack Randomized Trial; SSRI: Selective serotonin reuptake inhibitor;

STAR*D: Sequenced Treatment Alternatives to Relieve Depression; UC: Usual care.

\section{Competing interests}

The authors declare that they have no competing interests.

\section{Authors' contributions}

Both KEF and RMC contributed equally to the conception, writing, and revision of this manuscript. All authors read and approved the final manuscript.

\section{Authors' information}

Kenneth E. Freedland, Ph.D. is a Professor of Psychiatry and Psychology and the Associate Director of the Behavioral Medicine Center at Washington University School of Medicine in St. Louis, Missouri, USA. Robert M. Carney, Ph.D. is a Professor of Psychiatry and Psychology and the Director of the Behavioral Medicine Center at Washington University School of Medicine in St. Louis, Missouri, USA. Drs. Freedland and Carney have been collaborating since 1986 on research on the role and treatment of depression in patients with coronary heart disease or congestive heart failure.

Received: 14 November 2012 Accepted: 1 May 2013

Published: 15 May 2013

\section{References}

1. Charlson FJ, Stapelberg NJ, Baxter AJ, Whiteford HA: Should global burden of disease estimates include depression as a risk factor for coronary heart disease? BMC Med 2011, 9:47.

2. Meijer A, Conradi HJ, Bos EH, Thombs BD, van Melle JP, de JP: Prognostic association of depression following myocardial infarction with mortality and cardiovascular events: a meta-analysis of 25 years of research. Gen Hosp Psychiatry 2011, 33:203-216.

3. Barth J, Schumacher M, Herrmann-Lingen C: Depression as a risk factor for mortality in patients with coronary heart disease: a meta-analysis. Psychosom Med 2004, 66:802-813.

4. Nicholson A, Kuper $H$, Hemingway $H$ : Depression as an aetiologic and prognostic factor in coronary heart disease: a meta-analysis of 6362 events among 146538 participants in 54 observational studies. Eur Heart J 2006, 27:2763-2774.

5. van Melle JP, de Jonge P, Spijkerman TA, Tijssen JG, Ormel J, van Veldhuisen DJ, van den Brink RH, van den Berg MP: Prognostic association of depression following myocardial infarction with mortality and cardiovascular events: a meta-analysis. Psychosom Med 2004, 66:814-822.

6. Kuper H, Nicholson A, Kivimaki M, Aitsi-Selmi A, Cavalleri G, Deanfield JE, Heuschmann P, Jouven X, Malyutina S, Mayosi BM, Sans S, Thomsen T, Witteman JC, Hingorani AD, Lawlor DA, Hemingway $H$ : Evaluating the causal relevance of diverse risk markers: horizontal systematic review. BMJ 2009, 339:b4265.

7. Carney RM, Freedland KE, Miller GE, Jaffe AS: Depression as a risk factor for cardiac mortality and morbidity: a review of potential mechanisms. J Psychosom Res 2002, 53:897-902.

8. Skala JA, Freedland KE, Carney RM: Coronary heart disease and depression: a review of recent mechanistic research. Can J Psychiatry 2006, 51:738-745.

9. Carney RM, Freedland KE: Treatment-resistant depression and mortality after acute coronary syndrome. Am J Psychiatry 2009, 166:410-417.

10. Simon GE, Von KM: Medical co-morbidity and validity of DSM-IV depression criteria. Psychol Med 2006, 36:27-36.

11. Freedland KE, Lustman PJ, Carney RM, Hong BA: Underdiagnosis of depression in patients with coronary artery disease: the role of nonspecific symptoms. Int J Psychiatry Med 1992, 22:221-229.

12. Koenig HG, George LK, Peterson BL, Pieper CF: Depression in medically ill hospitalized older adults: prevalence, characteristics, and course of symptoms according to six diagnostic schemes. Am J Psychiatry 1997, 154:1376-1383.

13. Ward LC: Comparison of factor structure models for the Beck Depression Inventory-II. Psychol Assess 2006, 18:81-88. 
14. Quilty LC, Zhang KA, Bagby RM: The latent symptom structure of the Beck Depression Inventory-II in outpatients with major depression. Psychol Assess 2010, 22:603-608.

15. American Psychiatric Association: American Psychiatric Association, Task Force on DSM-IV, Diagnostic and Statistical Manual of Mental Disorders. 4th edition. Washington: DC: American Psychiatric Association; 2000. text revsion.

16. O'Keeffe N, Ranjith G: Depression, demoralisation or adjustment disorder? Understanding emotional distress in the severely medically ill. Clin Med 2007, 7:478-481.

17. Lespérance F, Frasure-Smith N, Talajic M: Major depression before and after myocardial infarction: its nature and consequences. Psychosom Med 1996, 58:99-110

18. Carney RM, Freedland KE, Steinmeyer B, Blumenthal JA, de Jonge P, Davidson KW, Czajkowski SM, Jaffe AS: History of depression and survival after acute myocardial infarction. Psychosom Med 2009, 71:253-259.

19. Davidson KW, Kupfer DJ, Bigger JT, Califf RM, Carney RM, Coyne JC, Czajkowski SM, Frank E, Frasure-Smith N, Freedland KE, Froelicher ES, Glassman AH, Katon WJ, Kaufmann PG, Kessler RC, Kraemer HC, Krishnan KR, Lespérance F, Rieckmann N, Sheps DS, Suls JM: National Heart, Lung, and Blood Institute Working Group: Assessment and treatment of depression in patients with cardiovascular disease: National Heart, Lung, and Blood Institute Working Group Report. Psychosom Med 2006, 68:645-650.

20. Spitzer RL, Kroenke K, Williams JB: Validation and utility of a self-report version of PRIME-MD: the PHQ primary care study, Primary Care Evaluation of Mental Disorders. Patient Health Questionnaire. JAMA 1999, 282:1737-1744

21. Kroenke K, Spitzer RL, Williams JB: The Patient Health Questionnaire-2: validity of a two-item depression screener. Med Care 2003, 41:1284-1292

22. Kroenke K, Strine TW, Spitzer RL, Williams JB, Berry JT, Mokdad AH: The PHQ-8 as a measure of current depression in the general population. J Affect Disord 2009, 114:163-173.

23. Beck AT, Ward CH, Mendelson M, Mock J, Erbaugh J: An inventory for measuring depression. Arch Gen Psychiatry 1961, 4:561-571.

24. Beck AT, Steer RA, Brown GK: Manual for the Beck Depression Inventory-II. San Antonio, TX: Psychological Corporation; 1996.

25. Robins LN, Wing J, Wittchen HU, Helzer JE, Babor TF, Burke J, Farmer A, Jablenski A, Pickens R, Regier DA, et al: The Composite International Diagnostic Interview, an epidemiologic instrument suitable for use in conjunction with different diagnostic systems and in different cultures. Arch Gen Psychiatry 1988, 45:1069-1077.

26. Freedland KE, Skala JA, Carney RM, Raczynski JM, Taylor CB, Mendes de Leon CF, Ironson G, Youngblood ME, Krishnan KR, Veith RC: The Depression Interview and Structured Hamilton (DISH): rationale, development, characteristics, and clinical validity. Psychosom Med 2002, 64:897-905.

27. Dao TK, Chu D, Springer J, Gopaldas RR, Menefee DS, Anderson T, Hiatt E, Nguyen Q: Clinical depression, posttraumatic stress disorder, and comorbid depression and posttraumatic stress disorder as risk factors for in-hospital mortality after coronary artery bypass grafting surgery. J Thorac Cardiovasc Surg 2010, 140:606-610.

28. Scherrer JF, Virgo KS, Zeringue A, Bucholz KK, Jacob T, Johnson RG, True WR, Carney RM, Freedland KE, Xian H, Caplan L, McDonald J, Eisen SA: Depression increases risk of incident myocardial infarction among Veterans Administration patients with rheumatoid arthritis. Gen Hosp Psychiatry 2009, 31:353-359.

29. Bush DE, Ziegelstein RC, Tayback M, Richter D, Stevens S, Zahalsky H, Fauerbach JA: Even minimal symptoms of depression increase mortality risk after acute myocardial infarction. Am J Cardiol 2001, 88:337-341.

30. Grace SL, Abbey SE, Kapral MK, Fang J, Nolan RP, Stewart DE: Effect of depression on five-year mortality after an acute coronary syndrome. Am J Cardiol 2005, 96:1179-1185.

31. Strik JJ, Honig A, Lousberg R, Denollet J: Sensitivity and specificity of observer and self-report questionnaires in major and minor depression following myocardial infarction. Psychosomatics 2001, 42:423-428.

32. Thombs BD, Magyar-Russell G, Bass EB, Stewart KJ, Tsilidis KK, Bush DE, Fauerbach JA, McCann UD, Ziegelstein RC: Performance characteristics of depression screening instruments in survivors of acute myocardial infarction: review of the evidence. Psychosomatics 2007, 48:185-194.

33. Bunevicius A, Staniute M, Brozaitiene J, Bunevicius R: Diagnostic accuracy of self-rating scales for screening of depression in coronary artery disease patients. J Psychosom Res 2012, 72:22-25.
34. McManus D, Pipkin SS, Whooley MA: Screening for depression in patients with coronary heart disease (data from the Heart and Soul Study). Am J Cardiol 2005, 96:1076-1081.

35. Carney RM, Rich MW, Freedland KE, Saini J, teVelde A, Simeone C, Clark K: Major depressive disorder predicts cardiac events in patients with coronary artery disease. Psychosom Med 1988, 50:627-633.

36. Frasure-Smith $N$, Lesperance F, Talajic M: Depression following myocardial infarction. Impact on 6-month survival. JAMA 1993 270:1819-1825

37. Kaufmann MW, Fitzgibbons JP, Sussman EJ, Reed JF 3rd, Einfalt JM, Rodgers JK, Fricchione GL: Relation between myocardial infarction, depression, hostility, and death. Am Heart J 1999, 138:549-554.

38. Carney RM, Blumenthal JA, Catellier D, Freedland KE, Berkman LF, Watkins LL, Czajkowski SM, Hayano J, Jaffe AS: Depression as a risk factor for mortality after acute myocardial infarction. Am J Cardiol 2003, 92:1277-1281.

39. Frasure-Smith $\mathrm{N}$, Lesperance $\mathrm{F}$ : Recent evidence linking coronary heart disease and depression. Can J Psychiatry 2006, 51:730-737.

40. Vieweg W, Hasnain M, Lesnefsky EJ, Turf EE, Pandurangi AK: Assessing the presence and severity of depression in subjects with comorbid coronary heart disease. Am J Med 2010, 123:683-690.

41. Krueger RF, Bezdjian S: Enhancing research and treatment of mental disorders with dimensional concepts: toward DSM-V and ICD-11. World Psychiatry 2009, 8:3-6.

42. Carney RM, Freedland KE, Jaffe AS: Insomnia and depression prior to myocardial infarction. Psychosom Med 1990, 52:603-609.

43. Hoen PW, Whooley MA, Martens EJ, Na B, van Melle JP, de Jonge P: Differential associations between specific depressive symptoms and cardiovascular prognosis in patients with stable coronary heart disease. J Am Coll Cardiol 2010, 56:838-844.

44. Hoen PW, Conradi HJ, Denollet J, Martens EJ, de Jonge P: Interview-based ratings of somatic and cognitive symptoms of depression and their impact on cardiovascular prognosis. Psychother Psychosom 2010, 79:319-320.

45. Linke SE, Rutledge T, Johnson BD, Vaccarino V, Bittner V, Cornell CE, Eteiba W, Sheps DS, Krantz DS, Parashar S, Bairey Merz CN: Depressive symptom dimensions and cardiovascular prognosis among women with suspected myocardial ischemia: a report from the National Heart, Lung, and Blood Institute-sponsored Women's Ischemia Syndrome Evaluation. Arch Gen Psychiatry 2009, 66:499-507.

46. Martens EJ, Hoen PW, Mittelhaeuser M, de Jonge P, Denollet J: Symptom dimensions of post-myocardial infarction depression, disease severity and cardiac prognosis. Psychol Med 2010, 40:807-814.

47. Smolderen KG, Spertus JA, Reid KJ, Buchanan DM, Krumholz HM, Denollet J, Vaccarino V, Chan PS: The association of cognitive and somatic depressive symptoms with depression recognition and outcomes after myocardial infarction. Circ Cardiovasc Qual Outcomes 2009, 2:328-337.

48. Roest AM, Carney RM, Freedland KE, Martens EJ, Denollet J, De Jonge P: Changes in cognitive versus somatic symptoms of depression and eventfree survival following acute myocardial infarction in the Enhancing Recovery In Coronary Heart Disease (ENRICHD) study. J Affect Disord 2013.

49. Barefoot JC, Brummett BH, Helms MJ, Mark DB, Siegler IC, Williams RB: Depressive symptoms and survival of patients with coronary artery disease. Psychosom Med 2000, 62:790-795.

50. Connerney I, Sloan RP, Shapiro PA, Bagiella E, Seckman C: Depression is associated with increased mortality 10 years after coronary artery bypass surgery. Psychosom Med 2010, 72:874-881.

51. de Jonge P, Ormel J, van den Brink RH, van Melle JP, Spijkerman TA, Kuijper A, van Veldhuisen DJ, van den Berg MP, Honig A, Crijns HJ, Schene AH: Symptom dimensions of depression following myocardial infarction and their relationship with somatic health status and cardiovascular prognosis. Am J Psychiatry 2006, 163:138-144.

52. Roest AM, Thombs BD, Grace SL, Stewart DE, Abbey SE, de Jonge P: Somatic/affective symptoms, but not cognitive/affective symptoms, of depression after acute coronary syndrome are associated with 12-month all-cause mortality. J Affect Disord 2011, 131:158-163.

53. Irvine J, Basinski A, Baker B, Jandciu S, Paquette M, Cairns J, Connolly S, Roberts R, Gent M, Dorian P: Depression and risk of sudden cardiac death after acute myocardial infarction: testing for the confounding effects of fatigue. Psychosom Med 1999, 61:729-737

54. Pedersen SS, Denollet J, Daemen J, van de Sande M, de Jaegere PT, Serruys PW, Erdman RA, van Domburg RT: Fatigue, depressive symptoms, and hopelessness as predictors of adverse clinical events following 
percutaneous coronary intervention with paclitaxel-eluting stents. J Psychosom Res 2007, 62:455-461.

55. Tully PJ, Winefield HR, Baker RA, Turnbull DA, de Jonge P: Confirmatory factor analysis of the Beck Depression Inventory-II and the association with cardiac morbidity and mortality after coronary revascularization. J Health Psychol 2011, 16:584-595.

56. Carney RM, Freedland KE: Is there a high-risk subtype of depression in patients with coronary heart disease? Curr Psychiatry Rep 2012, 14:1-7.

57. Kessler RC, Berglund P, Demler O, Jin R, Koretz D, Merikangas KR, Rush AJ, Walters EE, Wang PS: National Comorbidity Survey Replication: The epidemiology of major depressive disorder: results from the National Comorbidity Survey Replication (NCS-R). JAMA 2003, 289:3095-3105.

58. Hasin DS, Goodwin RD, Stinson FS, Grant BF: Epidemiology of major depressive disorder: results from the National Epidemiologic Survey on Alcoholism and Related Conditions. Arch Gen Psychiatry 2005, 62:1097-1106.

59. Rice JP, Rochberg N, Endicott J, Lavori PW, Miller C: Stability of psychiatric diagnoses, an application to the affective disorders. Arch Gen Psychiatry 1992, 49:824-830.

60. Ben-Zeev D, Young MA: Accuracy of hospitalized depressed patients' and healthy controls' retrospective symptom reports: an experience sampling study. J Nerv Ment Dis 2010, 198:280-285.

61. Carney RM, Freedland KE: Depression in patients with coronary heart disease. Am J Med 2008, 121:S20-S27.

62. Li C, Ford ES, Zhao G, Ahluwalia IB, Pearson WS, Mokdad AH: Prevalence and correlates of undiagnosed depression among U.S. adults with diabetes: the Behavioral Risk Factor Surveillance System, 2006. Diabetes Res Clin Pract 2009, 83:268-279.

63. Zuidersma $\mathrm{M}$, Thombs BD, de Jonge $\mathrm{P}$ : Onset and recurrence of depression as predictors of cardiovascular prognosis in depressed acute coronary syndrome patients: a systematic review. Psychother Psychosom 2011, 80:227-237.

64. Valkanova V, Ebmeier KP: Vascular risk factors and depression in later life: a systematic review and meta-analysis. Biol Psychiatry 2013, 73:406-413.

65. Alexopoulos GS: The vascular depression hypothesis: 10 years later. Biol Psychiatry 2006, 60:1304-1305.

66. Zuidersma M, Ormel J, Conradi HJ, de Jonge P: An increase in depressive symptoms after myocardial infarction predicts new cardiac events irrespective of depressive symptoms before myocardial infarction. Psychol Med 2012, 42:683-693.

67. Whooley MA, de Jonge P, Vittinghoff E, Otte C, Moos R, Carney RM, Ali S, Dowray S, Na B, Feldman MD, Schiller NB, Browner WS: Depressive symptoms, health behaviors, and risk of cardiovascular events in patients with coronary heart disease. JAMA 2008, 300:2379-2388.

68. Freedland KE, Carney RM, Skala JA: Depression and smoking in coronary heart disease. Psychosom Med 2005, 67:S42-S46.

69. Carney RM, Freedland KE, Eisen SA, Rich MW, Jaffe AS: Major depression and medication adherence in elderly patients with coronary artery disease. Health Psychol 1995, 14:88-90.

70. Gehi A, Haas D, Pipkin S, Whooley MA: Depression and medication adherence in outpatients with coronary heart disease: findings from the Heart and Soul Study. Arch Intern Med 2005, 165:2508-2513.

71. Rieckmann N, Burg MM, Kronish IM, Chaplin WF, Schwartz JE, Davidson KW: Aspirin adherence, depression and one-year prognosis after acute coronary syndrome. Psychother Psychosom 2011, 80:316-318.

72. Leifheit-Limson EC, Kasl SV, Lin H, Buchanan DM, Peterson PN, Spertus JA, Lichtman $\mathrm{JH}$ : Adherence to risk factor management instructions after acute myocardial infarction: the role of emotional support and depressive symptoms. Ann Behav Med 2012, 43:198-207.

73. Carney RM, Steinmeyer B, Freedland KE, Blumenthal JA, Stein PK, Steinhoff WA, Howells WB, Berkman LF, Watkins LL, Czajkowski SM, Domitrovich PP, Burg MM, Hayano J, Jaffe AS: Nighttime heart rate and survival in depressed patients post acute myocardial infarction. Psychosom Med 2008, 70:757-763.

74. Carney RM, Freedland KE, Stein PK, Miller GE, Steinmeyer B, Rich MW, Duntley SP: Heart rate variability and markers of inflammation and coagulation in depressed patients with coronary heart disease. J Psychosom Res 2007, 62:463-467.

75. Carney RM, Blumenthal JA, Freedland KE, Stein PK, Howells WB, Berkman LF, Watkins LL, Czajkowski SM, Hayano J, Domitrovich PP, Jaffe AS: Low heart rate variability and the effect of depression on post-myocardial infarction mortality. Arch Intern Med 2005, 165:1486-1491.
76. Miller GE, Stetler CA, Carney RM, Freedland KE, Banks WA: Clinical depression and inflammatory risk markers for coronary heart disease. Am J Cardiol 2002, 90:1279-1283.

77. Empana JP, Sykes DH, Luc G, Juhan-Vague I, Arveiler D, Ferrieres J, Amouyel P, Bingham A, Montaye M, Ruidavets JB, Haas B, Evans A, Jouven X, Ducimetiere P, PRIME Study Group: Contributions of depressive mood and circulating inflammatory markers to coronary heart disease in healthy European men: the Prospective Epidemiological Study of Myocardial Infarction (PRIME). Circulation 2005, 111:2299-2305.

78. Whooley MA, Caska CM, Hendrickson BE, Rourke MA, Ho J, Ali S: Depression and inflammation in patients with coronary heart disease: findings from the Heart and Soul Study. Biol Psychiatry 2007, 62:314-320.

79. Vaccarino V, Johnson BD, Sheps DS, Reis SE, Kelsey SF, Bittner V, Rutledge T, Shaw LJ, Sopko G, Bairey Merz CN: National Heart, Lung, and Blood Institute: Depression, inflammation, and incident cardiovascular disease in women with suspected coronary ischemia: the National Heart, Lung, and Blood Institute-sponsored WISE study. J Am Coll Cardiol 2007, 50:2044-2050

80. Frasure-Smith N, Lesperance F, Irwin MR, Talajic M, Pollock BG: The relationships among heart rate variability, inflammatory markers and depression in coronary heart disease patients. Brain Behav Immun 2009, 23:1140-1147.

81. Bjerkeset O, Romild U, Smith GD, Hveem K: The associations of high levels of C-reactive protein with depression and myocardial infarction in 9258 women and men from the HUNT population study. Psychol Med 2011, 41:345-352.

82. Duivis HE, De JP, Penninx BW, Na BY, Cohen BE, Whooley MA: Depressive symptoms, health behaviors, and subsequent inflammation in patients with coronary heart disease: prospective findings from the heart and soul study. Am J Psychiatry 2011, 168:913-920.

83. Poole L, Dickens C, Steptoe A: The puzzle of depression and acute coronary syndrome: reviewing the role of acute inflammation. J Psychosom Res 2011, 71:61-68.

84. Kendler KS, Gardner CO, Fiske A, Gatz M: Major depression and coronary artery disease in the Swedish twin registry: phenotypic, genetic, and environmental sources of comorbidity. Arch Gen Psychiatry 2009, 66:857-863.

85. Carney RM, Freedland KE: Depression, mortality, and medical morbidity in patients with coronary heart disease. Biol Psychiatry 2003, 54:241-247.

86. Ruo B, Rumsfeld JS, Hlatky MA, Liu H, Browner WS, Whooley MA: Depressive symptoms and health-related quality of life: the Heart and Soul Study. JAMA 2003, 290:215-221.

87. Kurdyak PA, Chong A, Gnam WH, Goering P, Alter DA: Depression and self-reported functional status: impact on mortality following acute myocardial infarction. J Eval Clin Pract 2011, 17:444-451.

88. Dodson JA, Arnold SV, Reid KJ, Gill TM, Rich MW, Masoudi FA, Spertus JA, Krumholz HM, Alexander KP: Physical function and independence 1 year after myocardial infarction: observations from the Translational Research Investigating Underlying disparities in recovery from acute Myocardial infarction: Patients' Health status registry. Am Heart J 2012, 163:790-796.

89. Steffens DC, O'Connor CM, Jiang WJ, Pieper CF, Kuchibhatla MN, Arias RM, Look A, Davenport C, Gonzalez MB, Krishnan KR: The effect of major depression on functional status in patients with coronary artery disease. J Am Geriatr Soc 1999, 47:319-322.

90. Guico-Pabia CJ, Fayyad RS, Soares CN: Assessing the relationship between functional impairment/recovery and depression severity: a pooled analysis. Int Clin Psychopharmacol 2012, 27:1-7.

91. Katon WJ: Epidemiology and treatment of depression in patients with chronic medical illness. Dialogues Clin Neurosci 2011, 13:7-23.

92. McCaffery JM, Frasure-Smith N, Dubé MP, Théroux P, Rouleau GA, Duan Q, Lespérance F: Common genetic vulnerability to depressive symptoms and coronary artery disease: a review and development of candidate genes related to inflammation and serotonin. Psychosom Med 2006, 68:187-200

93. Scherrer JF, Xian H, Bucholz KK, Eisen SA, Lyons MJ, Goldberg J, Tsuang M, True WR: A twin study of depression symptoms, hypertension, and heart disease in middle-aged men. Psychosom Med 2003, 65:548-557.

94. Xian H, Scherrer JF, Franz CE, McCaffery J, Stein PK, Lyons MJ, Jacobsen K, Eisen SA, Kremen WS: Genetic vulnerability and phenotypic expression of depression and risk for ischemic heart disease in the Vietnam era twin study of aging. Psychosom Med 2010, 72:370-375. 
95. Glassman AH, O'Connor CM, Califf RM, Swedberg K, Schwartz P, Bigger JT Jr, Krishnan KR, van Zyl LT, Swenson JR, Finkel MS, Landau C, Shapiro PA, Pepine CJ, Mardekian J, Harrison WM, Barton D, Mclvor M: Sertraline Antidepressant Heart Attack Randomized Trial (SADHEART) Group: Sertraline treatment of major depression in patients with acute MI or unstable angina. JAMA 2002, 288:701-709.

96. Jiang W, Davidson JR: Antidepressant therapy in patients with ischemic heart disease. Am Heart J 2005, 150:871-881.

97. Lespérance F, Frasure-Smith N, Koszycki D, Laliberté MA, van Zyl LT, Baker B, Swenson JR, Ghatavi K, Abramson BL, Dorian P, Guertin MC: CREATE Investigators: Effects of citalopram and interpersonal psychotherapy on depression in patients with coronary artery disease: the Canadian Cardiac Randomized Evaluation of Antidepressant and Psychotherapy Efficacy (CREATE) trial. JAMA 2007, 297:367-379.

98. Vieweg WV, Julius DA, Fernandez A, Wulsin LR, Mohanty PK, Beatty-Brooks M, Hasnain M, Pandurangi AK: Treatment of depression in patients with coronary heart disease. Am J Med 2006, 119:567-573.

99. Taylor D, Meader N, Bird V, Pilling S, Creed F, Goldberg D: Pharmacological interventions for people with depression and chronic physical health problems: systematic review and meta-analyses of safety and efficacy. Br J Psychiatry 2011, 198:179-188.

100. Berkman LF, Blumenthal J, Burg M, Carney RM, Catellier D, Cowan MJ, Czajkowski SM, DeBusk R, Hosking J, Jaffe A, Kaufmann PG, Mitchell P, Norman J, Powell LH, Raczynski JM, Schneiderman N: Enhancing Recovery in Coronary Heart Disease Patients Investigators (ENRICHD): Effects of treating depression and low perceived social support on clinical events after myocardial infarction: the Enhancing Recovery in Coronary Heart Disease Patients (ENRICHD) Randomized Trial. JAMA 2003, 289:3106-3116.

101. Davidson KW, Rieckmann N, Clemow L, Schwartz JE, Shimbo D, Medina V, Albanese G, Kronish I, Hegel M, Burg MM: Enhanced depression care for patients with acute coronary syndrome and persistent depressive symptoms: coronary psychosocial evaluation studies randomized controlled trial. Arch Intern Med 2010, 170:600-608.

102. Mathew SJ: Treatment-resistant depression: recent developments and future directions. Depress Anxiety 2008, 25:989-992.

103. Huijbregts KM, van der Feltz-Cornelis CM, van Marwijk HW, de Jong FJ, van der Windt DA, Beekman AT: Negative association of concomitant physical symptoms with the course of major depressive disorder: a systematic review. J Psychosom Res 2010, 68:511-519.

104. Preskorn SH: Treatment options for the patient who does not respond well to initial antidepressant therapy. J Psychiatr Pract 2009, 15:202-210.

105. Gaynes BN, Warden D, Trivedi MH, Wisniewski SR, Fava M, Rush AJ: What did STAR*D teach us? Results from a large-scale, practical, clinical trial for patients with depression. Psychiatr Serv 2009, 60:1439-1445.

106. Sinyor M, Schaffer A, Levitt A: The sequenced treatment alternatives to relieve depression (STAR*D) trial: a review. Can J Psychiatry 2010, 55:126-135.

107. Trivedi RB, Nieuwsma JA, Williams JW Jr: Examination of the utility of psychotherapy for patients with treatment resistant depression: a systematic review. J Gen Intern Med 2011, 26:643-650.

doi:10.1186/1741-7015-11-131

Cite this article as: Freedland and Carney: Depression as a risk factor for adverse outcomes in coronary heart disease. BMC Medicine 2013 11:131.

\section{Submit your next manuscript to BioMed Central and take full advantage of:}

- Convenient online submission

- Thorough peer review

- No space constraints or color figure charges

- Immediate publication on acceptance

- Inclusion in PubMed, CAS, Scopus and Google Scholar

- Research which is freely available for redistribution 